\title{
Traumatic bile duct neuroma presenting with acute cholangitis: A case report and review of literature
}

\author{
Priti Lalchandani ${ }^{1}$, Abraham Korn ${ }^{1}$, Jiajie G. Lu³, Samuel W. French ${ }^{3}$, Linda Hou $^{2}$, and Kathryn T. Chen ${ }^{1}$ \\ Departments of ${ }^{1}$ General Surgery, ${ }^{2}$ Internal Medicine, and ${ }^{3}$ Pathology, Harbor-UCLA Medical Center, Torrance, CA, USA
}

Traumatic neuroma of the biliary tree has been previously reported as isolated case reports. In literature, these typically present following prior liver transplant or cholecystectomy, wherein the bile ducts have been disrupted in some form. Here we report the case of a 41-year old male who initially presented with acute cholangitis ten years after an open cholecystectomy complicated by a bile leak. Endoscopic retrograde cholangiography revealed a stricture within the mid distal common hepatic duct. The patient temporarily resolved his initial episode with stent placement, and he was eventually taken to the operating room for bile duct resection and hepaticojejunostomy given a persistent stricture and concern for underlying malignancy. Final pathology demonstrated a traumatic bile duct neuroma. This unusual entity should be considered in patients with benign appearing strictures presenting years after surgery, and awareness may aid in preoperative counseling as well. (Ann Hepatobiliary Pancreat Surg 2019;23:282-285)

Key Words: Bile duct neuroma; Biliary stricture; Biliary obstruction

\section{INTRODUCTION}

Traumatic neuroma of the biliary tree has been reported since the $1920 \mathrm{~s}^{1}$ but remain an uncommon cause of obstructive cholangitis. They form as a proliferation of nerves following an inciting injury to the bile duct, typically resection or injury. We present a case of a patient who initially presented with acute ascending cholangitis secondary to a biliary stricture 10 years after open cholecystectomy. After failing endoscopic management, he was taken to the operating room (OR) for bile duct resection and hepaticojejunostomy. Final pathology revealed traumatic biliary neuroma.

\section{CASE}

A 41 year old man initially presented through the emergency department at our hospital with 2-day history of epigastric pain radiating to his right upper quadrant and right flank, non-bilious emesis, 20 pound weight loss over two months, and tea-colored urine. His past surgical history was significant for having undergone an open cholecystectomy 10 years prior. He related that there was some sort of biliary injury around the time of operation, and he had undergone re-operations and procedures for this injury. However, he did not know the details of his history, and records were not available to us. Nevertheless, he stated that he eventually recovered, and in the past ten years was living his life without any sort of sequelae from this event.

On presentation to our hospital, he was noted to be significantly jaundiced, and in septic shock. Laboratory findings were significant for a leukocytosis of 16.2 , total bilirubin $7.8 \mathrm{mg} / \mathrm{dl}$, bilirubin $4.7 \mathrm{mg} / \mathrm{dl}$, and otherwise normal transaminase enzymes. Contrast tomography (CT) scan of the abdomen and pelvis with intravenous (IV) contrast revealed intra- and extrahepatic biliary dilation. The patient was diagnosed with acute cholangitis and underwent urgent endoscopic retrograde cholangio-pancreatography (ERCP) for decompression. ERCP demonstrated a $3-4 \mathrm{~cm}$ stricture

Received: December 26, 2018; Revised: February 11, 2019; Accepted: February 21, 2019

Corresponding author: Kathryn T. Chen

Division of Surgical Oncology, Department of General Surgery, Harbor-UCLA Medical Center, 1000 W. Carson Street, Bldg 1E, Torrance, CA 90502, USA

Tel: +1-424-306-8091, Fax: +1-310-782-1562, E-mail: kchen6@dhs.lacounty.gov

Copyright (C) 2019 by The Korean Association of Hepato-Biliary-Pancreatic Surgery

This is an Open Access article distributed under the terms of the Creative Commons Attribution Non-Commercial License (http://creativecommons.org/ licenses/by-nc/4.0) which permits unrestricted non-commercial use, distribution, and reproduction in any medium, provided the original work is properly cited. Annals of Hepato-Biliary-Pancreatic Surgery - pISSN: 2508-5778 - elSSN: 2508-5859 
in the common hepatic duct (CHD) approximately $2 \mathrm{~cm}$ below the bifurcation (Fig. 1). A $10 \mathrm{~mm} \times 10 \mathrm{~cm}$ fully covered metal biliary stent was placed across the stricture, with subsequent normalization of his total and direct bilirubin values $(0.7 \mathrm{mg} / \mathrm{dl}$ and $0.1 \mathrm{mg} / \mathrm{dl}$, respectively).

After he was clinically stable, he underwent repeat ERCP on the same admission and brushings were obtained of the stricture. Endoscopic ultrasound did not demonstrate an underlying mass. Pathology from the brushings demonstrated a glandular focus with high proliferative index and MUC1 positive staining, features concerning, but not definitive, for neoplastic change. He was discharged from the hospital and then underwent a repeat ERCP as an outpatient several months later. A persistent stricture was noted. The prior stent was withdrawn and a high grade bile leak was noted at that site of stricture. This was re-

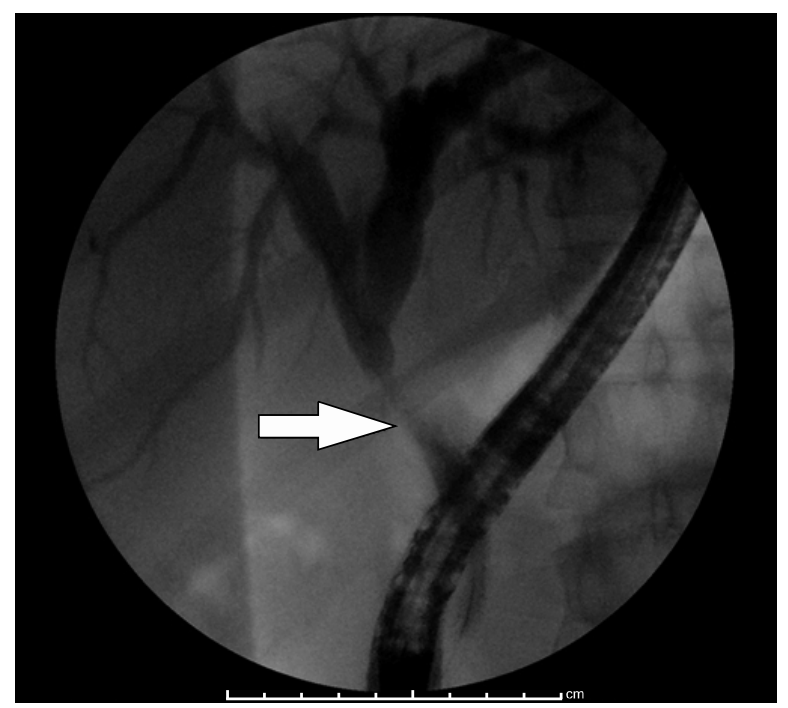

Fig. 1. ERCP showing common bile duct stricture. solved with the placement of a fully covered stent.

Given the persistent stricture and concern for neoplasm, he was referred to the Surgical Oncology service for definitive management. The patient was taken to the operating room for open bile duct resection and hepaticojejunostomy. The patient's post-operative course was uneventful, and he was discharged home on post-operative day 6. Final surgical pathology revealed traumatic neuroma of the bile duct with positive S100 stains and no evidence of malignancy (Fig. 2). He has since followed up with us in clinic, and is doing well.

\section{DISCUSSION}

Extra-hepatic bile duct strictures in an adult can occur in the setting of malignant or benign biliary tumors, postoperatively after upper abdominal surgeries (anastomotic ischemia or iatrogenic injury), secondary to chronic diseases (primary sclerosing cholangitis or chronic pancreatitis), or without clear etiology. Patients can have a wide range of presentation; they can be asymptomatic, have only liver function enzyme abnormalities, or develop symptoms such as pruritus or obstructive jaundice or cholangitis. $^{2}$

The most common cause of primary biliary tumors is invasive adenocarcinoma, ${ }^{3}$ whereas benign tumors are much less common and only account for $6 \%$ of all biliary tumors. A particular type of benign tumor is a biliary neuroma, of which two types exist: primary neuromas and traumatic neuromas (also known as amputation neuromas). Primary neuromas are rare and develop secondary to axonal proliferation within the nerve epineurium, whereas
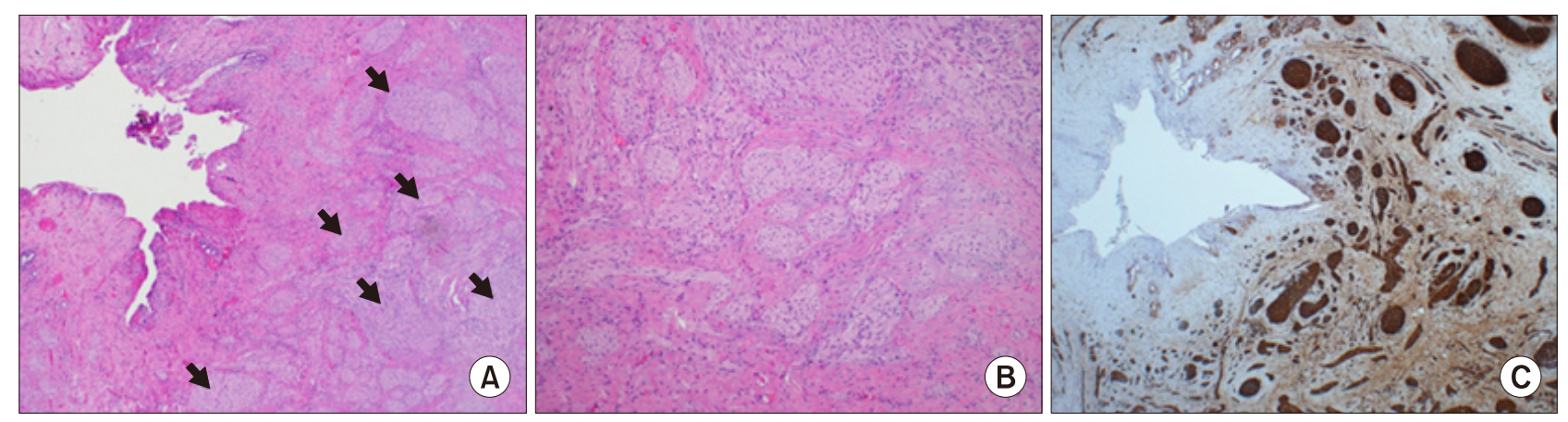

Fig. 2. Histopathology of traumatic bile duct neuroma. (A) Section of the distal common bile duct showing a haphazard arrangement of nerves (arrows) surrounding the duct (H\&E, 80× magnification). No neoplasm is seen. (B) Higher magnification of the nerves $(\mathrm{H} \& \mathrm{E}, 200 \times)$. (C) The nerves stain positively for S-100 (40× magnification). 
Table 1. Published case reports of traumatic neuromas following surgery over the last 15 years

\begin{tabular}{|c|c|c|c|}
\hline Case report & Initial surgery & Symptoms at presentation & $\begin{array}{l}\text { Months to } \\
\text { presentation }\end{array}$ \\
\hline Capovilla et al. ${ }^{9}$ & Open cholecystectomy & Obstructive jaundice & 3 \\
\hline Chantranuwat et al. & Open cholecystectomy & Obstructive jaundice & 36 \\
\hline Cheng et al. ${ }^{2}$ & Hepaticojejunostomy & Obstructive jaundice & 36 \\
\hline Cimaschi et al. & Open cholecystectomy & Obstructive jaundice & 60 \\
\hline De Rosa et al. $^{3}$ & Open cholecystectomy & Obstructive jaundice & 24 \\
\hline Elkhatib et al. ${ }^{10}$ & Open cholecystectomy & RUQ pain & 20 \\
\hline Herrera et al. ${ }^{11}$ & Transplant & $\begin{array}{l}\text { Obstructive jaundice }(80 \%) \text {, abnormal } \\
\text { LFTs }^{c}(13.3 \%) \text {, incidental finding }(6.6 \%)\end{array}$ & $4^{\mathrm{e}}$ \\
\hline Hotta et al. ${ }^{12}$ & Open cholecystectomy with $\mathrm{CBD}^{\mathrm{a}}$ exploration & Obstructive jaundice & 204 \\
\hline Hyman et al. $^{13}$ & Open cholecystectomy & Obstructive jaundice & 36 \\
\hline Iannelli et al. ${ }^{14}$ & Open cholecystectomy & Obstructive jaundice & 144 \\
\hline Kim et al. $^{7}$ & Open cholecystectomy & Bile duct nodule & 204 \\
\hline Koh et al. ${ }^{15}$ & Choledochojejunostomy & Polypoid mass in CBD & 120 \\
\hline Mentha et al. ${ }^{16}$ & Orthotopic liver transplantation & Obstructive jaundice & $13.5^{\mathrm{b}}$ \\
\hline Moreno Antón et al. & Laparoscopic cholecystectomy & Obstructive jaundice & 36 \\
\hline Mrklić et al. ${ }^{17}$ & Open cholecystectomy & Obstructive jaundice & 264 \\
\hline Nagafuchi et al. & Laparoscopic cholecystectomy & Obstructive jaundice & 8 \\
\hline Nagata et al. & Laparoscopic cholecystectomy & Obstructive jaundice & 2 \\
\hline Navez et al. ${ }^{18}$ & Transplant & Obstructive jaundice & $69^{\mathrm{d}}$ \\
\hline Paquette et al. ${ }^{19}$ & Open cholecystectomy & Obstructive jaundice and mass in $\mathrm{CBD}$ & 540 \\
\hline Rastogi et al. ${ }^{6}$ & Open cholecystectomy & Obstructive jaundice & 60 \\
\hline Saint-Paul et al. ${ }^{20}$ & Open cholecystectomy & Cholangitis & 48 \\
\hline Sleiman et al. ${ }^{4}$ & Open cholecystectomy & Obstructive jaundice & 96 \\
\hline Terzi et al. & Orthotopic liver transplantation & Abnormal LFTs ${ }^{c}$ & 7 \\
\hline Toyonaga et al. ${ }^{8}$ & Open cholecystectomy & Bile duct nodule & 552 \\
\hline
\end{tabular}

${ }^{\mathrm{a} C o m m o n}$ Bile Duct (CBD)

${ }^{\mathrm{b}}$ Average of 2 patients reported

${ }^{c}$ Liver Function Test (LFT)

${ }^{\mathrm{d}}$ Average of 5 patients reported

${ }^{\mathrm{e}}$ Average of 15 patients reported

traumatic neuromas are due to disruption of the epineurium, resulting in a chronic proliferation of nerve fibers in the connective tissue surrounding the nerve. Pathologically, these tumors are characterized by presence of spindle cells and are positive for immunohistochemistry for S100, a marker for neurofilament protein. ${ }^{3}$

One of the first reported cases reported of a traumatic neuroma was in 1928, followed by the first case of obstructive jaundice secondary to a traumatic biliary neuroma published in 1930 by the Mayo Clinic in Rochester, Minnesota. ${ }^{1}$ Since that time, only a limited number of cases have been reported in literature. Any pathology involving the biliary tree, such as infection, trauma or biliary surgery can lead to a biliary neuroma, ${ }^{4}$ but most reported cases in the literature occur following open cholecystectomy. Only a few cases secondary to laparoscopic cholecystectomy have been reported.
In general, benign strictures of the biliary tree secondary to ischemia present within months to 2 years of the initial surgery, although delayed presentations have been reported. ${ }^{5}$ On the other hand, traumatic neuromas typically manifest more than 2 years from the initial insult. A PubMed search was conducted on published case reports and series of post-surgical traumatic biliary neuromas in the past 15 years. Twenty-four publications were identified and available for review, with a total of 43 patients reported (Table 1). The initial surgeries were primarily open cholecystectomy or transplant, although rarely neuromas were reported after uncomplicated laparoscopic cholecystectomies as well. The time interval from surgery to diagnosis of traumatic biliary neuroma ranged from 2 months to 46 years, with the median time to diagnosis of 5 years. In the subgroup of patients who underwent open cholecystectomy, the median time from surgery to pre- 
sentation was more than 12 years.

Accurate preoperative diagnosis of neuroma can be difficult. Many patients in case reports listed were thought to have an underlying malignancy, ${ }^{6}$ with elevated CA19-9 and imaging studies concerning for an infiltrative or neoplastic process. In several case reports, a defined enhancing nodule on CT was described, ${ }^{7}$ which underscored the concern for malignancy. More recently, a neuroma was diagnosed preoperatively by boring biopsy with cholangioscopy $^{8}$; this particular patient was asymptomatic and was able to avoid surgery. Unfortunately, as jaundice is a common presenting symptom and because malignancy often cannot be definitively excluded, most patients undergo surgical intervention. However, awareness of traumatic neuromas may aid preoperative work up and planning, as well as patient counseling.

\section{REFERENCES}

1. Comfort MW, Walters W. Intermittent jaundice due to neuroma of cystic and common bile ducts. Ann Surg 1931;93:1142-1145.

2. Cheng Y, Jia Q, Xiong X, Cheng N. Traumatic bile duct neuroma after resection of hilar cholangiocarcinoma. Clin Res Hepatol Gastroenterol 2014;38:127-128.

3. De Rosa A, Gomez D, Zaitoun AM, Cameron IC. Neurofibroma of the bile duct: a rare cause of obstructive jaundice. Ann R Coll Surg Engl 2013;95:e38-e40.

4. Sleiman YA, Hassoun ZA, Nasser HA, Abs L, Allouch M. A late unusual complication after an open cholecystectomy: amputation neuroma of the CBD causing obstructive jaundice. Int $\mathrm{J}$ Surg Case Rep 2017;39:123-125.

5. Lillemoe KD, Pitt HA, Cameron JL. Current management of benign bile duct strictures. Adv Surg 1992;25:119-174.

6. Rastogi A, Bihari C, Arora A, Sinha PK, Chattopadhyay TK, Kishore GS. Hilar traumatic neuroma masquerading as Klatskin tumor. Trop Gastroenterol 2015;36:54-56.

7. Kim HH, Koh YS, Seoung JS, Hur YH, Cho CK. Education and imaging. Hepatobiliary and pancreatic: traumatic bile duct neuroma. J Gastroenterol Hepatol 2011;26:1465.

8. Toyonaga $\mathrm{H}$, Taniguchi Y, Inokuma T, Imai Y. Traumatic bile duct neuroma diagnosed by boring biopsy with cholangioscopy. Gastrointest Endosc 2018;87:1361-1362.

9. Capovilla M, Lazure T, Lorand I, Carton E, Rocher L, Pelletier $\mathrm{G}$, et al. [Post-cholecystectomy amputation neuroma of the common bile duct with obstructive jaundice]. Gastroenterol Clin Biol 2005;29:79-81. French.

10. Elkhatib I, Shah N, Savides TJ. Neuroma of the bile duct mimicking cholangiocarcinoma. Gastrointest Endosc 2017;85:11001101.

11. Herrera L, Martino E, Rodríguez-Sanjuán JC, Castillo J, Casafont F, González F, et al. Traumatic neuroma of extrahepatic bile ducts after orthotopic liver transplantation. Transplant Proc 2009; 41:1054-1056.

12. Hotta T, Kobayashi Y, Taniguchi K, Naka T, Johata K, Sahara $\mathrm{M}$, et al. A traumatic neuroma of the bile duct: a case report. Hepatogastroenterology 2004;51:39-42.

13. Hyman J, Wilczynski SP, Schwarz RE. Extrahepatic bile duct stricture and elevated CA 19-9: malignant or benign? South Med J 2003;96:89-92.

14. Iannelli A, Fabiani P, Karimdjee BS, Converset S, Saint-Paul MC, Gugenheim J. Traumatic neuroma of the cystic duct with biliary obstruction. Report of a case. Acta Gastroenterol Belg 2003;66:28-29.

15. Koh DW, Lee WJ, Kim JH, Choi JI, Kim SH, Hong EK, et al. [Amputation neuroma mimicking common bile duct cancer: a case report]. Korean J Gastroenterol 2008;52:32-36. Korean.

16. Mentha G, Rubbia-Brandt L, Orci L, Becker C, Giostra E, Majno $\mathrm{P}$, et al. Traumatic neuroma with biliary duct obstruction after orthotopic liver transplantation. Transplantation 1999;67:177-179.

17. Mrklić I, Pogorelić Z, Bendić A, Tomić S. Post-cholecystectomy amputation neuroma mimicking common bile duct carcinoma. Acta Gastroenterol Belg 2011;74:363-365.

18. Navez J, Golse N, Bancel B, Rode A, Ducerf C, Mezoughi S, et al. Traumatic biliary neuroma after orthotopic liver transplantation: a possible cause of "unexplained" anastomotic biliary stricture. Clin Transplant 2016;30:1366-1369.

19. Paquette IM, Suriawinata AA, Ornvold K, Gardner TB, Axelrod DA. Neuroma of the bile duct: a late complication after cholecystectomy. J Gastrointest Surg 2009;13:1517-1519.

20. Saint-Paul MC, Benchimol D, Dumas R, Michiels JF, Hofman $\mathrm{P}$, van den Broucke $\mathrm{X}$, et al. [Neuroma of the common bile duct]. Ann Gastroenterol Hepatol (Paris) 1993;29:65-67. French. 